\title{
Anosognosia and Anosodiaphoria in Mild Cognitive Impairment and Alzheimer's Disease
}

\author{
Maria Lindau ${ }^{a} \quad$ Randall Bjork ${ }^{b}$ \\ a Department of Psychology, Stockholm University, Stockholm, Sweden; ${ }^{b}$ Colorado Springs \\ Neurological Associates, Colorado Springs, Colo., USA
}

\author{
Key Words \\ Dementia $\cdot$ Disease progression $\cdot$ Behavior $\cdot$ Neuropsychology
}

\begin{abstract}
Aims: To evaluate the occurrence of anosognosia (lack of awareness) and anosodiaphoria (insouciance) in mild cognitive impairment (MCI) and Alzheimer's disease (AD) and to evaluate the influence of a worsening of dementia on these phenomena. Methods: A self-evaluation scale was used assessing degrees of anosognosia and anosodiaphoria; furthermore, a neuropsychological assessment and statistical analyses with nonparametric tests which could cope with data on an ordinal scale level and small samples were employed. Results: Cognitive ability was lower in AD $(n=9)$ than in MCI patients $(n=12)$, but AD patients self-rated lower cognitive disabilities, which is interpreted as one relative sign of anosognosia in AD. Awareness of the reasons for cognitive problems was also lower in AD, which is considered as another sign of anosognosia. The main pattern in MCI found that the higher the awareness, the lower the cognitive ability. In AD low awareness paralleled low cognitive functioning. Anosodiaphoria was present in $A D$ but not in MCI. Conclusion: According to the literature anosognosia and anosodiaphoria seem to increase with progression of dementia from $\mathrm{MCI}$ as a result of right hemispheric alterations.

\section{Introduction}

Consciousness is one of the most difficult neuropsychological concepts to define, since it refers to the essence of being alive as a human being. Thinking is a complex activity, and consciousness has been defined as 'integrated information' [1, p. 216], referring to the psychological mechanisms that continuously interweave ample, always changing, sensory infor- 
Lindau and Bjork: Anosognosia and Anosodiaphoria in Mild Cognitive Impairment and Alzheimer's Disease

mation and make it possible for the individual to keep him or her constantly updated about the information interwoven as a gestalt [2]. Lack of illness awareness or insight may be conceived as a deficit in consciousness and has been studied throughout medical history [3-5]. Babinski [6] in 1914 coined the term anosognosia to characterize a state of a lack of consciousness of left-sided hemiplegia, which he hypothesized originated in a right hemispheric lesion, in one of his patients [7]. Later, anosognosia has come to signify a unawareness of a variety of disturbances in 'sensory, perceptual, motor, affective, or cognitive functioning' [8, p. 570; 9]. Not recognizing being ill may present serious problems for the patients, reducing their willingness to be compliant with treatment and to realize the practical consequences of the disturbance for their everyday life [10].

The neuroanatomical correlates of anosognosia in Alzheimer's disease (AD) have most often been studied with functional imaging [single photon emission computed tomography (SPECT) and positron emission tomography (PET)] [11]. There is a lot of evidence that anosognosia in $\mathrm{AD}$ is associated with right-sided abnormalities $[8,10,12,13]$ in the frontal region [12-16]. Aberrant metabolic activity has also been seen in the temporoparietal junction, which has been found to be 'consistent with impairment in self-referential processes and perspective taking in $\mathrm{AD}^{\prime}$ [17, p. 588].

Not many studies have been conducted on the prevalence and neuronal correlates of anosognosia in mild cognitive impairment (MCI) [18], which is a state of failing cognition that may precede a later conversion to $\operatorname{AD}[19,20]$. However, one study reports the frequency of anosognosia in MCI to be 54\% [18]. There are indications that anosognosia intensifies with a worsening of $\mathrm{AD}[13,21]$, and unawareness of memory deficits in $\mathrm{MCI}$ has also been suggested as a possible precursor to $\mathrm{AD}$ [22]. Data about the prevalence of anosognosia in AD vary considerably. A range between 20 and $80 \%$ has been reported [5], but frequencies such as $46.7 \%$ of the sample [23] and 43 of 57 patients [12] have also been estimated.

Another trait that Babinski [6] observed in 1914 was that some hemiplegic patients recognized the presence of their paralysis but seemed unconcerned about it and trivialized the malfunction. Babinski named this attitude ofinsouciance anosodiaphoria, which resembles la belle indifference earlier described by Breuer and Freud [24, p. 135] and which today in DSM-IV is considered as a conversion symptom [25, 26].

Among the neurodegenerative disorders, frontal anosodiaphoria, meaning lack of emotional concern' [27, p. 1690], is particularly salient in the behavioral variant of frontotemporal dementia $[27,28]$. No study has been found indicating anosodiaphoria in AD. However, since there are strong indications of a frontal involvement in anosognosia in $\mathrm{AD}$, the possibility of anosodiaphoria in $\mathrm{AD}$ also needs to be taken into consideration. Another reason is that anosodiaphoria may be mistaken for anosognosia, which can be exemplified by an interpretation of Korsakoff's description [29] in 1889 of severe amnesia as a 'lack of concern' for the symptoms, as a sign of anosognosia [5, p. 7].

Thus, there are indications that anosognosia is present in MCI and in dementia, particularly in $\mathrm{AD}$, where it has been regarded as an early symptom of $\mathrm{AD}$, and that anosodiaphoria is particularly indicative of the behavioral variant of frontotemporal dementia. Although behavioral and neuropsychiatric symptoms in AD are well documented [5, 30, 31], seemingly no attention has been paid to the probability of anosodiaphoria in this disorder. There also seems to exist a risk that anosodiaphoria may be mistaken for anosognosia. No study of anosodiaphoria in MCI has been found.

The aim of the present study has been to contribute to the conceptual clarity concerning the distinction between anosognosia and anosodiaphoria, to investigate whether there are signs of anosognosia as well as anosodiaphoria in MCI and AD and to evaluate the influence of progression of cognitive, mnemonic and executive disabilities on the level of anosognosia and anosodiaphoria in MCI and AD. 
Lindau and Bjork: Anosognosia and Anosodiaphoria in Mild Cognitive Impairment and Alzheimer's Disease

Table 1. Demography of MCI and AD patients

\begin{tabular}{|c|c|c|c|c|c|c|c|c|c|c|}
\hline Group & $\mathrm{n}$ & $\begin{array}{l}\text { Gender } \\
(\mathrm{F} / \mathrm{M})\end{array}$ & $\begin{array}{l}\text { Age }(\mathrm{F} / \mathrm{M}) \text {, } \\
\text { years }\end{array}$ & $\begin{array}{l}\mathrm{p} \\
\text { value }\end{array}$ & $\begin{array}{l}\text { Age group } \\
(\mathrm{F}+\mathrm{M}), \\
\text { years }\end{array}$ & $\begin{array}{l}\mathrm{p} \\
\text { value }\end{array}$ & $\begin{array}{l}\text { Education } \\
(\mathrm{F} / \mathrm{M}) \text {, } \\
\text { years }\end{array}$ & $\begin{array}{l}\mathrm{p} \\
\text { value }\end{array}$ & $\begin{array}{l}\text { Education } \\
\text { group (F + } \\
\text { M), years }\end{array}$ & $\begin{array}{l}\mathrm{p} \\
\text { value }\end{array}$ \\
\hline $\begin{array}{l}\text { MCI } \\
\mathrm{AD}\end{array}$ & $\begin{array}{r}12 \\
9\end{array}$ & $\begin{array}{l}5 / 7 \\
8 / 1\end{array}$ & $\begin{array}{l}72.8 / 74.1 \\
79.6 / 85.0\end{array}$ & $\begin{array}{l}\text { n.s. } \\
-\end{array}$ & $\begin{array}{l}73.6 \\
80.2\end{array}$ & 0.05 & $\begin{array}{l}13.2 / 17.1 \\
11.9 / 13.0\end{array}$ & $\begin{array}{l}\text { n.s. } \\
-\end{array}$ & $\begin{array}{l}15.5 \\
12.0\end{array}$ & 0.04 \\
\hline
\end{tabular}

Values represent means. $\mathrm{F}$ = Females; $\mathrm{M}$ = males.

\section{Materials and Methods}

\section{Participants}

The participants were recruited among clinical $\mathrm{MCI}$ and $\mathrm{AD}$ outpatients at the Colorado Springs Neurological Associates, PC (CSNA), Colorado Springs, Colo., USA. The MCI sample was mixed insofar as the subjects exhibited different degrees of memory decline and deterioration of other cognitive functions. The enrollment of the subjects was nonconsecutive because of the largely varying degrees of cognitive decline among the patients. A consecutive enrollment would have risked that patients that were not testable due to intellectual disabilities would have been contacted in vain.

Patients finally included were those that were willing to participate, who were estimated to be able to perform on the tests and where relatives were positive about their participation. All the patients in the study had been informed about their diagnoses during the previous visits to their physician.

The initial sample included 31 patients with cortical as well as subcortical changes. However, the number of the patients with suspected frontotemporal pathology (2 patients), Parkinson's disease ( 3 patients) and ischemic disorders (5 patients) that were available during the data-collecting phase of the study (1 month, 2011) was too small, and therefore they had to be excluded from the study. The final sample consisted of $12 \mathrm{MCI}$ patients and 9 AD patients (table 1). A follow-up study is planned with an increased number of patients in each of the mentioned diagnostic categories.

The mean age of the MCI group was significantly lower than that of the AD group. The educational level was generally rather elevated and significantly higher in the MCI group than in the AD group. Analyses of the effects of gender on education in the AD group were not meaningful, since the distribution of the sexes was uneven, with an overrepresentation of females in this diagnostic category.

\section{Diagnostic Criteria}

Patients were diagnosed according to the requirements of the International Classification of Diseases, 9th Revision, Clinical Modification (ICD-9-CM) [32]. Indications for MCI were a decrease in cognition for age, and for $\mathrm{AD}$ they were an insidious onset of memory/ cognitive/orientation/behavioral symptoms, imaging evidence [magnetic resonance imaging (MRI)] of cerebral atrophy, a spacious third ventricle, slowing of the posterior dominant rhythm on EEG (alpha less than $8.5 \mathrm{~Hz}$ ) and normal National Institutes of Health (NIH) laboratory screening, including serology for Treponema pallidum (syphilis). Definite AD diagnosis must be based on autopsy [33]. 
Lindau and Bjork: Anosognosia and Anosodiaphoria in Mild Cognitive Impairment and Alzheimer's Disease

\section{Definitions}

Cognitive awareness was understood here as a state of mind where information from different sensory systems is put together to a mental entirety [1]. Anosognosia was thus defined as a loss of or an abated awareness of symptoms, their roots and implications for life, and anosodiaphoria was defined as a reduction or a lack of botheration for this altered state of mind and situation [28]. The inclusion of the association with illness and consequences for everyday life in the anosognosia definition is based on an elaboration of a previous study [34]. For reasons of simplicity, anosognosia was used synonymously with expressions such as a lack of insight and a lack of awareness, and anosodiaphoria with expressions such as unconcern, insouciance and their equivalents. A thorough elaboration of the semantic correspondence of these synonyms would go beyond the scope of this investigation.

Living in the past, or shortcomings in adapting one's self-image to current circumstances, has been mentioned as a component of anosognosia in AD [35]. In frontotemporal dementia and $\mathrm{AD}$ patients 'a failure to update their self image after disease onset' has been identified as a characteristic trait for the diseases [36, p. 632]. Therefore, orientation about one's own age and reminiscence about one's profession (previous or current) have been included in the interview (see below) as relevant aspects of the anosognosia complex.

\section{Measures}

Anosognosia and Anosodiaphoria

A structured interview was conducted to assess the levels of anosognosia and anosodiaphoria, the Anosognosia and Anosodiaphoria scale (A\&A scale, Appendix 1). The interview guide is a revision and a development of a previously published guide used for assessing the loss of insight into frontotemporal dementia [34]. In the present study, it consisted of ten questions, where the answers were self-rated by the patients. The awareness part of the scale, aimed at catching signs of anosognosia, consisted of two questions concerning autobiographical data (question 1: age, question 2: earlier or present profession; the correctness of the answers to the question about present or previous profession was checked against the charts or with relatives). One question (question 3) about how the days are spent and whether the patient has made any changes in his or her way of living was asked to establish whether the patient thought that everything was as before and kept up old interests despite obvious signs that this would not be cognitively possible. The fourth question concerned awareness of the diagnosis, and there was a follow-up question (question 5) about what was understood about the diagnosis. The next question (question 6) was pertinent to subjectively experienced degrees of cognitive symptoms and the following question (question 7) to self-rated degrees of problems associated with cognition. Question 8 concerned the reasons for cognitive problems and whether problems noted could be associated with a relevant diagnosis or illness. The last question (question 10) in this section was about measures taken to adapt. Patients experiencing cognitive disabilities may have a need for adjustments, and alterations can therefore serve as a sign of awareness. If a patient does not subjectively experience any difficulties, although they may objectively be present, he or she may not find that there is any need for change whatsoever [34]. The anosodiaphoria subscale included a question where the patients were asked to rate their feelings in terms of worries about their cognition (question 9).

The interview questions were asked according to the protocol, and the participants were then requested to make self-ratings according to the scoring alternatives, which were explained verbally by the examiner. In that way, the subjective experiences of the participants were assessed. The scores usually ranged from 1 to 3 points. 
Estimations made by close informants may be used as a basis for comparisons with selfreports. A discrepancy score between self-evaluations and caregivers' ratings can serve as an indication of anosognosia [37]. Since no informant scoring was available in the present study, evaluations of the occurrence of anosognosia and anosodiaphoria in MCI and AD were made through comparisons of the self-ratings on the A\&A scale between the groups themselves and versus their neuropsychological test scores. Comparisons with neuropsychological test scores have also been a previously used method to assess anosognosia [8]. Here, the relation between the cognitive performance levels in MCI and AD was compared to obtain an estimate of which level could be considered as lower and which as higher. Relatively low awareness scores versus comparatively low cognitive performance levels have served as indications of anosognosia. Relatively low rates on the emotional evaluative part of the scale and comparatively low cognitive levels have been used as criteria of anosodiaphoria.

Neuropsychological Assessment

The cognitive level, including memory, was investigated with a short battery of neuropsychological tests, comprising semantic memory: Information (Wechsler Adult Intelligence Scale - 4th ed., WAIS-IV [38]); spatial thinking/executive function: Clock Drawing (free-hand drawing of ten past eleven [39]), Rey-Osterrieth Complex Figure, copying [40, 41]; executive function: verbal creativity/fluency: Controlled Oral Word Association Test (FAS) [42]; spatial creativity: Design Fluency (DF) [43] and psychomotor function/visual scanning/set shifting with Trail Making Test (TMT), parts A and B, number of connections [44]; working memory: rote memory - Digit Span Forward, rote memory/mental flexibility - Digit Span Backward (WAIS-IV) [38]; verbal and spatial episodic memory: Rey Auditory Verbal Learning Test (RAVLT) - learning, delayed recall $30 \mathrm{~min}$ and noting repetitions of already mentioned words in the wordlist as well as confabulations [41], and Rey-Osterrieth (immediate recall [40, 41]). Finally, after the testing had been concluded, the participants were asked to recall as many tasks as possible that they had been doing during the investigation; this was classified as a task for recall from the verbal episodic memory (for scoring principles, see Appendix 1). The recall task about what had been done during the test session was inspired by the Rivermead Behavioral Memory Test.

\section{Statistical Analyses}

Data were analyzed with IBM SPSS Statistics, version 19. Demographic information was evaluated with Student's t test. Internal consistency and reliability of the scale were tested with Cronbach's alpha, where rates between 0.70 and 0.95 have been identified as acceptable, but where an alpha value of 0.90 has been suggested as an acceptable upper limit [45]. Since the neuropsychological information was on the ordinal scale level and the samples sizes were small, data have been investigated with nonparametric methods. Differences between MCI and $\mathrm{AD}$ patients on the $\mathrm{A} \& \mathrm{~A}$ scale and on neuropsychological tests were assessed with the Mann-Whitney U test. The relationships between the scores on the A\&A scale and cognitive test results were estimated with Spearman's rank correlation coefficient test. The significance level was $p=0.05$. The study was approved by the Memorial Health System, Colorado Springs, Colo., USA (IRB No. 110305).

\section{Results}

Cronbach's alpha for all the items on the A\&A scale except item 9, which concerned anosodiaphoria, was 0.76 , and this indicates a good internal consistency and reliability of the instrument. The mean ranks of the answers to the interview questions showed that the ratings 
Table 2. Scores of MCI and AD patients on the A\&A scale

\begin{tabular}{|c|c|c|c|c|c|}
\hline Question & Group & Median & Min-Max & Mean rank & $\mathrm{p}$ value \\
\hline \multicolumn{6}{|l|}{ Awareness } \\
\hline \multirow[t]{2}{*}{1 (age) } & MCI & 3 & $2-3$ & 13.1 & \\
\hline & $\mathrm{AD}$ & 2 & $1-3$ & 8.2 & 0.03 \\
\hline \multirow[t]{2}{*}{2 (profession) } & MCI & 3 & $1-3$ & 12.1 & \\
\hline & $\mathrm{AD}$ & 3 & $1-3$ & 9.6 & n.s. \\
\hline \multirow[t]{2}{*}{3 (change in spending days) } & MCI & 3 & $2-3$ & 12.6 & \\
\hline & $\mathrm{AD}$ & 2 & $2-3$ & 8.8 & n.s. \\
\hline \multirow[t]{2}{*}{4 (diagnosis) } & MCI & 3 & $1-3$ & 12.9 & \\
\hline & $\mathrm{AD}$ & 1 & $1-3$ & 8.4 & n.s. \\
\hline \multirow[t]{2}{*}{5 (diagnostic understanding) } & MCI & 3 & $1-3$ & 12.6 & \\
\hline & $\mathrm{AD}$ & 1 & $1-3$ & 8.8 & n.s. \\
\hline \multirow[t]{2}{*}{6 (degree of cognitive symptoms) } & MCI & 2 & $1-3$ & 12.9 & \\
\hline & $\mathrm{AD}$ & 2 & $1-2$ & 8.5 & 0.05 \\
\hline \multirow[t]{2}{*}{7 (degree of problems) } & MCI & 2 & $1-3$ & 11.5 & \\
\hline & $\mathrm{AD}$ & 2 & $1-2$ & 10.3 & n.s. \\
\hline \multirow[t]{2}{*}{8 (reasons for cognitive problems) } & MCI & 2 & $1-4$ & 13.0 & \\
\hline & $\mathrm{AD}$ & 1 & $1-2$ & 8.3 & 0.04 \\
\hline \multirow[t]{2}{*}{10 (adjustment) } & MCI & 2 & $1-3$ & 11.1 & \\
\hline & $\mathrm{AD}$ & 2 & $1-3$ & 10.9 & n.s. \\
\hline \multicolumn{6}{|l|}{ Emotional evaluation } \\
\hline \multirow[t]{2}{*}{9 (feelings about cognition) } & MCI & 2 & $1-3$ & 12.3 & \\
\hline & $\mathrm{AD}$ & 1 & $1-3$ & 9.2 & n.s. \\
\hline
\end{tabular}

Medians, minimum and maximum scores, mean ranks, and differences in mean ranks between MCI and AD are shown.

on the awareness items were generally higher in the MCI group than in the AD group, although they were significant only for three of the ten items. The MCI patients were considerably better oriented about their own age (question 1), rated a higher degree of cognitive shortcomings (question 6) and could more often associate their cognitive problems with a relevant diagnosis and illness (question 8) than the AD patients (table 2).

Neuropsychological performance levels (table 3) according to the mean ranks were significantly higher in MCI than in AD patients on tests of general knowledge/semantic memory (Information) and selectively higher on tests of spatial thinking/executive function (Clock Drawing, Rey-Osterrieth), executive/psychomotor function: spatial creativity (DF), set shifting (TMT B), short-term memory - rote memory/mental flexibility (Digit Span Backward (B), repetition), two aspects of verbal episodic memory (RAVLT), and recall of the tasks which had been performed during the test session as well as visuospatial episodic memory (ReyOsterrieth).

All the items on the A\&A scale were significantly correlated to different constellations of neuropsychological tests (table 4) except for the Rey-Osterrieth Complex Figure, copying condition, the number of connections on the set shifting test, TMT B and RAVLT, delayed recall (30 $\mathrm{min}$ ) as well as the number of repetitions of the words on RAVLT, delayed recall, where no associations with the scale items were found.

The correlation analysis between significantly differentiating A\&A scale items (questions 1, 6 and 8) and significantly differentiating neuropsychological test results indicated more numerous associations in the $\mathrm{AD}$ group than in the MCI group. Totally, in the $\mathrm{AD}$ group six of the ten comparisons revealed more numerous correlations than in the MCI group (table 4). 


\section{DOI: $10.1159 / 000369132$}

Lindau and Bjork: Anosognosia and Anosodiaphoria in Mild Cognitive Impairment and Alzheimer's Disease

Table 3. Performance of MCI and AD patients on neuropsychological tests

\begin{tabular}{|c|c|c|c|c|}
\hline Cognitive test & Group & Median & Mean rank & $\mathrm{p}$ value \\
\hline \multicolumn{5}{|l|}{ Semantic memory } \\
\hline \multirow[t]{2}{*}{ Information } & MCI & 12.0 & 13.5 & \\
\hline & $\mathrm{AD}$ & 4.0 & 7.6 & 0.03 \\
\hline \multicolumn{5}{|l|}{ Visuospatial/executive function } \\
\hline \multirow[t]{2}{*}{ Clock Drawing } & MCI & 5.0 & 13.2 & \\
\hline & $\mathrm{AD}$ & 4.0 & 8.1 & 0.05 \\
\hline \multirow[t]{2}{*}{ CF, copying, points } & MCI & 31.5 & 13.5 & \\
\hline & $\mathrm{AD}$ & 24.0 & 7.6 & 0.03 \\
\hline \multicolumn{5}{|l|}{ Executive and psychomotor function } \\
\hline \multirow{2}{*}{ FAS, totally } & MCI & 25.0 & 12.1 & \\
\hline & $\mathrm{AD}$ & 13.0 & 9.6 & n.s. \\
\hline \multirow[t]{2}{*}{ DF, no correct } & MCI & 26.0 & 14.2 & \\
\hline & $\mathrm{AD}$ & 2.0 & 6.7 & 0.006 \\
\hline \multirow[t]{2}{*}{ DF, no figurative } & MCI & 2.0 & 11.1 & \\
\hline & $\mathrm{AD}$ & 1.0 & 10.8 & n.s. \\
\hline \multirow{2}{*}{ TMT A, connections } & MCI & 24.0 & 12.1 & \\
\hline & AD & 24.0 & 9.6 & n.s. \\
\hline \multirow[t]{2}{*}{ TMT B, connections } & MCI & 22.5 & 12.8 & \\
\hline & $\mathrm{AD}$ & 7.0 & 7.1 & 0.03 \\
\hline \multicolumn{5}{|l|}{ Short-term memory } \\
\hline \multirow[t]{2}{*}{ Digit Span F, total sum } & MCI & 10.0 & 11.8 & \\
\hline & AD & 9.0 & 9.9 & n.s. \\
\hline \multirow[t]{2}{*}{ Digit Span B, total sum } & $\mathrm{MCI}$ & 7.0 & 13.3 & \\
\hline & $\mathrm{AD}$ & 6.0 & 7.9 & 0.05 \\
\hline \multicolumn{5}{|l|}{ Verbal episodic memory } \\
\hline \multirow[t]{2}{*}{ RAVLT, learning, no words } & $\mathrm{MCI}$ & 24.0 & 13.5 & \\
\hline & $\mathrm{AD}$ & 14.0 & 7.6 & 0.03 \\
\hline \multirow[t]{2}{*}{ RAVLT, learning, no repetitions } & MCI & 0.50 & 13.0 & \\
\hline & $\mathrm{AD}$ & 0.00 & 8.4 & 0.05 \\
\hline \multirow[t]{2}{*}{ RAVLT, learning, no confabulations } & MCI & 0.50 & 11.8 & \\
\hline & $\mathrm{AD}$ & 0.00 & 9.9 & n.s. \\
\hline \multirow[t]{2}{*}{ RAVLT, recall, no words } & MCI & 5.0 & 13.1 & \\
\hline & $\mathrm{AD}$ & 0.00 & 5.7 & 0.003 \\
\hline \multirow[t]{2}{*}{ RAVLT, recall, repetitions } & $\mathrm{MCI}$ & 0.00 & 10.0 & \\
\hline & $\mathrm{AD}$ & 0.00 & 10.0 & n.s. \\
\hline \multirow[t]{2}{*}{ Recall of testing tasks } & MCI & 4.5 & 14.3 & \\
\hline & $\mathrm{AD}$ & 0.00 & 6.7 & 0.005 \\
\hline \multicolumn{5}{|l|}{ Visuospatial episodic memory } \\
\hline \multirow[t]{2}{*}{$\mathrm{CF}$, recall, points } & MCI & 7.5 & 13.8 & \\
\hline & $\mathrm{AD}$ & 2.0 & 7.2 & 0.02 \\
\hline
\end{tabular}

Medians, mean ranks and differences between mean ranks between $\mathrm{MCI}$ and $\mathrm{AD}$ are shown. $\mathrm{CF}=$ Rey-Osterrieth Complex Figure; Digit Span F = forward; Digit Span B = backward.

In the MCI category the analysis showed that the higher the awareness of age (question 1), the higher the verbal episodic memory (RAVLT). In the AD group there was a positive correlation between awareness of age and general knowledge/semantic memory (Information), and spatial creativity (DF). Knowledge about one's own age also correlated positively with spatial episodic memory in the AD category. 
Table 4. Correlations between significantly different items on the A\&A scale and significantly different neuropsychological tests for $\mathrm{MCI}$ and $\mathrm{AD}$ patients

\begin{tabular}{|c|c|c|c|c|}
\hline Question & Group & Cognitive test & $\mathrm{p}$ value & $\mathrm{r}$ \\
\hline \multicolumn{5}{|l|}{ Awareness } \\
\hline \multirow{4}{*}{1 (age) } & MCI & RAVLT, learning & 0.02 & 0.648 \\
\hline & $\mathrm{AD}$ & Information & 0.04 & 0.688 \\
\hline & & DF, correct & 0.04 & 0.699 \\
\hline & & $\mathrm{CF}$, recall, points & 0.02 & 0.763 \\
\hline \multirow[t]{2}{*}{6 (degree of cognitive symptoms) } & MCI & - & - & - \\
\hline & $\overline{\mathrm{AD}}$ & DF, correct & 0.02 & 0.746 \\
\hline \multirow[t]{3}{*}{8 (reasons for cognitive problems) } & MCI & Information & 0.02 & -0.679 \\
\hline & & Clock Drawing & 0.002 & -0.788 \\
\hline & $\overline{\mathrm{AD}}$ & - & - & - \\
\hline
\end{tabular}

In MCI the estimation of the degree of cognitive problems (question 6) was not associated with any result in the neuropsychological tests. In AD there was a relationship meaning that the larger the amount of subjectively experienced cognitive problems, the higher the spatial creativity (DF). The MCI patients were more prone to associate their cognitive decline with illness (question 8) than the AD patients, and there was a negative association showing that the higher the insight into the roots of the mental decline, the lower the general knowledge and spatial orientation (Clock Drawing). In the AD group there were no associations between this question and cognition.

The pattern in the relations between the nonsignificant items on the A\&A scale and the levels on significantly differentiating neuropsychological tests was the same as between the significant A\&A items and the cognitive tests, i.e. more numerous correlations in AD than in MCI (table 5). There were no connections between the awareness of profession (question 2) and cognition in the MCI group, but there were connections in the AD group, where it correlated positively with the test of semantic memory and the spatial episodic memory.

Regarding question 3, the analysis indicated negative correlations in MCI, meaning the higher the number of changes that had been made because of cognitive malfunction, the lower the spatial orientation. In AD the positive association with DF appeared also in connection with question 1. Concerning awareness of diagnosis (question 4), there was a negative association in $\mathrm{MCI}$, implying the higher the knowledge of diagnosis, the lower the general knowledge and spatial orientation. In AD the awareness of diagnosis was positively related to different aspects of episodic memory. In MCI the understanding of the meaning of the diagnosis (question 5) was negatively correlated with the same tests as in question 4. In AD the associations meant the higher the diagnostic understanding, the higher parts of the verbal episodic memory. The evaluation of the degree of problems associated with cognitive decline (question 7) in the MCI category was positively related to spatial as well as verbal episodic memory. Data also revealed that the higher the experienced degree of problems in AD, the higher the executive function (DF) and results on the test of verbal episodic memory. The adjustment subscale (question 10) showed no associations in $\mathrm{MCI}$, but they were shown in AD with spatial orientation/executive ability, and short-term and verbal episodic memory.

Question 9 disclosed no associations with cognition in MCI, but in AD there were positive relations to spatial creativity and verbal episodic memory. 
Table 5. Correlations between nonsignificantly different items on the A\&A scale and significantly different neuropsychological tests for MCI and AD patients

\begin{tabular}{|c|c|c|c|c|}
\hline Question & Group & Cognitive test & $\mathrm{p}$ value & $\mathrm{r}$ \\
\hline \multicolumn{5}{|l|}{ Awareness } \\
\hline \multirow[t]{3}{*}{2 (profession) } & $\underline{\mathrm{MCI}}$ & - & - & - \\
\hline & $\mathrm{AD}$ & Information & 0.02 & 0.735 \\
\hline & & $\mathrm{CF}$, recall & 0.04 & 0.702 \\
\hline \multirow[t]{2}{*}{3 (change in spending days) } & MCI & Clock Drawing & 0.01 & -0.689 \\
\hline & $\mathrm{AD}$ & $\mathrm{DF}$, correct & 0.02 & 0.740 \\
\hline \multirow[t]{4}{*}{4 (diagnosis) } & MCI & Information & 0.03 & -0.617 \\
\hline & & Clock Drawing & 0.01 & -0.689 \\
\hline & $\mathrm{AD}$ & RAVLT, learning & 0.03 & 0.707 \\
\hline & & Recall, testing tasks & 0.01 & 0.779 \\
\hline \multirow[t]{4}{*}{5 (diagnostic understanding) } & MCI & Information & 0.03 & -0.617 \\
\hline & & Clock Drawing & 0.01 & -0.689 \\
\hline & $\mathrm{AD}$ & RAVLT, learning & 0.03 & 0.725 \\
\hline & & Recall, testing tasks & 0.01 & 0.798 \\
\hline \multirow[t]{4}{*}{7 (degree of problems) } & MCI & $\mathrm{CF}$, recall & 0.008 & 0.719 \\
\hline & & Recall, testing tasks & 0.002 & 0.802 \\
\hline & $\overline{\mathrm{AD}}$ & DF, correct & 0.01 & 0.796 \\
\hline & & RAVLT, learning & 0.003 & 0.866 \\
\hline \multirow[t]{4}{*}{10 (adjustment) } & MCI & - & - & - \\
\hline & $\mathrm{AD}$ & Clock Drawing & 0.02 & 0.746 \\
\hline & & Digit Span B, total sum & 0.04 & 0.685 \\
\hline & & Recall, testing tasks & 0.02 & 0.739 \\
\hline \multicolumn{5}{|l|}{ Emotional evaluation } \\
\hline \multirow[t]{3}{*}{9 (feelings about cognition) } & MCI & - & - & - \\
\hline & $\overline{\mathrm{AD}}$ & DF, correct & 0.04 & 0.685 \\
\hline & & RAVLT, learning & 0.003 & 0.857 \\
\hline
\end{tabular}

\section{Discussion}

The MCI patients subjectively experienced a higher degree of cognitive deficits than the AD patients, although the neuropsychological testing showed that semantic memory, spatial thinking, spatial creativity, set shifting, selectively short-term memory and essential parts of the episodic memory were considerably higher in MCI than in AD. Likewise, the awareness of age was higher in $\mathrm{MCI}$ than in $\mathrm{AD}$, which means that the autobiographical memory in this respect was better preserved in MCI than in AD. This supports the clinical diagnoses of the participants in these diagnostic groups.

The understanding that the current cognitive problems were due to a specific diagnosis or illness was also higher in MCI than in AD, that is the MCI patients could anchor their intellectual shortcomings in a disease or diagnosis in quite another way than the AD patients, who - if they to some extent admitted deficiencies - more often did not know where their deficits originated from.

There were more associations between the A\&A scale items and neuropsychological performance levels in AD than in MCI. One striking trait in the correlation analyses is that the MCI pattern is characterized by associations between on the one hand the A\&A scale items and on the other hand memory and spatial functions. In AD a similar pattern appears, but with 
the addition of associations with tests of frontal lobe functions (DF, RAVLT repetitions - a sign of dysexecutivity - and short-term memory). This may signify a progression of the neurodegeneration in the $\mathrm{AD}$ group to a frontal lobe engagement.

In the current study MCI patients rated larger cognitive problems than $\mathrm{AD}$ patients (question 6). Previous findings concerning self-ratings of cognitive hardship are contradictory. Lamentations about loss of memory have been found to increase concomitantly with cognitive decline in MCI [46], which fits well with the pattern in the MCI group, where the negative correlations generally imply that the higher the awareness is, the lower is the cognitive ability. This pattern of negative correlations disappears in AD, where the associations are positive and predominantly so with episodic memory and executive functions.

In the literature there is evidence that MCI patients overrate their cognitive shortcomings, when contrasted with evaluations made by close informants [37]. Since there was no control group, or caregivers' assessments, to compare with in the present study, it is impossible to judge whether the expressed higher levels of cognitive deficits or problems in the MCI group are signs of an overestimation of deficits or not. However, relative to the MCI patients, the AD patients underrated their cognitive symptoms, an observation that is strengthened by their cognitive skills being in several respects lower than those of the MCI patients. This relative underreporting of intellectual insufficiencies in AD is here interpreted as a sign of anosognosia, which is congruent with earlier findings that anosognosia is associated with a reduced awareness of memory due to frontal lobe disturbances [47]. Thus, there is also evidence of a frontal lobe engagement in anosognosia even in $\mathrm{AD}$, not just in frontotemporal dementia $[11,17]$.

From a definitional point of view, an overrating of deficits does not qualify as a sign of anosognosia, since anosognosia is the same as a reduction or lack of awareness in the sense of not being aware of a loss. An overrating of difficulties could rather be a sign of an increase in anxiety, which together with an increase in aggression-hostility and a decline in extraversion has been documented with Swedish Universities Scales of Personality as changes of personality traits in subjective cognitive impairment and MCI [48].

It has also been found that subjects with suspected dementia/MCI tend to overvalue their memory capabilities relative to healthy controls [49]. An overestimation of skills has likewise been traced in $\mathrm{AD}$, where it has been demonstrated that this group of patients tends to exaggerate their visuospatial and memory capabilities relative to controls. However, self-evaluation mistakes were even made by the control subjects, who underrated their levels of attention and overrated well-overlearned, automatized motor performance and eyesight [50], which underlines the difficulties to obtain reliable control data in this field.

The awareness of the roots of cognitive decline (question 8) is considerably lower in $\mathrm{AD}$ than in MCI. Compared to the fact that all AD patients had been informed about their diagnoses and consistently had lower cognitive levels than the MCI patients, this may be interpreted as another sign of anosognosia in the AD group. The AD patients may to some extent be aware of their cognitive symptoms, but they do not know where they come from. It is a kind of knowledge 'that is all in the air'.

Memory impairment itself has also been reported as a reason for anosognosia in $\mathrm{MCI}$ as well as AD [51-53], and it has been described as self-evident that it is impossible to be updated on malfunction if the event when the cognition did not work has fallen into oblivion [47]. This indicates that anosognosia can also be due to a loss of memory and not just to executive frontal lobe retrieval dysfunctions. Unawareness of memory deficits [53] due to posteromedial hypoperfusion characteristic for AD changes has also been suggested as a marker for future progression to AD [22].

There were no significant differences between the diagnostic groups in the degree of anosodiaphoria (question 9), but in the AD group the correlation analysis indicated that the 
lower/higher the worries about cognition, the lower/higher the objective measures of spatial creativity and verbal episodic memory, which here is conceived as a sign of anosodiaphoria in AD. Anosodiaphoria has mostly been studied in frontotemporal dementia. As reported by Mendez and Shapira [28], most findings indicate that a hypoperfusion in the right frontal area may account for anosognosia in this disorder.

The increase in $\mathrm{AD}$ to a more or less global influence of cognitive dysfunctions on the awareness and emotional reactions may reflect the progressive nature of this neurodegenerative disorder. The longer the disease progresses, the larger the effects of executive and other types of cognitive dysfunctions on awareness and emotional engagement. The finding that anosognosia seems to be related to the severity of $\mathrm{AD}$ is consistent with several previous studies [7, 15, 54-57]. Considering the overweight in connections between executive and memory functions foremost in $\mathrm{AD}$ and to some extent even in $\mathrm{MCI}$, the results are however most consistent with earlier findings that not just the degree of dementia can explain anosognosia in $\mathrm{AD}$, but that frontal lobe dysfunctions and memory decline may be particularly decisive parameters behind anosognosia $[12,58]$.

Limitations of the study are the restricted number of participants and the lack of data from close informants as a basis for comparisons with the patients' self-ratings, which limits the possibilities to evaluate the occurrence of anosognosia/anosodiaphoria in MCI and AD and of course reduces the generalizability of the results. One way to solve the problem with the lack of informant data would have been to see which of the patients had developed AD at follow-up and use the others as controls (in enlarged samples). However, so far no systematic monitoring of a possible conversion to dementia has been done. The test of disease progression is to be carried out in the follow-up study, which has not yet started. To match the restricted numbers of participants in the present study, data have been analyzed with nonparametric methods, known to be robust techniques for the use in small samples [59], that is in groups with less than 20 participants [41]. Nonparametric methods are tailored to deal with small samples, also taking into consideration often-appearing problems associated with restricted numbers of participants, such as skewness in the normal distribution, and allowing sporadic differences to be significant (which may disappear in larger samples). In contrast, many of the patterns found in the study fit well with previous findings in the literature, which indicates that the present results do not seem to stem from occasional significances originating in statistical anomalies due to small sample sizes. Another limitation is the fact that the A\&A scale just includes one item concerning anosodiaphoria and should have comprised more questions concerning this topic. Despite the limited attention to this topic in the scale, this single item all the same revealed an association with cognitive decline in the AD group.

To conclude, regardless of an in many respects lower cognitive ability than in $\mathrm{MCI}$, the $\mathrm{AD}$ patients rated lower cognitive disabilities relative to the MCI patients, which is here interpreted as one sign of anosognosia in $\mathrm{AD}$. The awareness of the reasons for cognitive problems was also lower in $\mathrm{AD}$, which is considered as another sign of anosognosia in this disease group. Symptoms of anosodiaphoria were present in AD but not in MCI. Anosognosia and anosodiaphoria seem to increase with the progression of MCI to dementia but in a context of aggravating neurodegeneration; especially dysexecutivity and memory dysfunction seem to account for anosognosia as well as anosodiaphoria. The general outcome of the study is well consistent with previous findings in the field [12].

Babinski's hypothesis [6] in 1914 that anosognosia may be associated with right hemispheric lesions has repeatedly been confirmed in the literature. Since previous findings have mostly identified right hemispheric changes as the roots of anosognosia as well as anosodiaphoria, it is plausible that the signs of anosognosia and anosodiaphoria in the present study may reflect an involvement of an underlying right-sided neurodegeneration, probably with 
different right-sided regional localization for these two types of abnormalities. Empirical neuroimaging evidence is necessary to confirm this assumption.

One suggestion for future research is the development of an anosognosia-anosodiaphoria scale that allows the establishment of cutoff values between what should be considered as normal levels of self-rating of disabilities and associated aspects and what should be considered as deviant, allowing to evaluate what should be understood as an absence of and degrees of anosognosia and anosodiaphoria. Cutoff scores for when cognitive decline starts to influence awareness would also be very useful.

\section{Acknowledgements}

This work was supported by The Swedish Foundation for International Cooperation in Research and Higher Education (STINT) under the grant number IB 2010-4501, the Department of Psychology, Stockholm University, Stockholm, Sweden, and Colorado Springs Neurological Associates, PC (CSNA), Colorado Springs, Colo., USA. We would like to thank Lilianne Eninger, Department of Psychology and the collaborators at the CSNA, particularly Cynthia Trujillo, Laurence J. Adams Jr., and Deanna Johnson, for their valuable contributions to the investigation.

\section{Disclosure Statement}

The authors declare no financial conflicts of interest with regard to this study.

\section{Appendix 1}

\section{Protocol}

Date of the investigation

Subject code:

\section{Introduction}

During this investigation I am going to ask you questions, and to ask you to perform tasks. Some of the tasks are answered verbally, others with the help of paper and pencil. Do you have any questions?

\section{Interview}

\section{How old are you?}

$\square$

Correct

3 points
Not correct - one year's error 2 points $\square$

Not correct - several years' errors 1 point 


\section{DOI: $10.1159 / 000369132$}

(C) 2014 S. Karger AG, Base www.karger.com/dee

Lindau and Bjork: Anosognosia and Anosodiaphoria in Mild Cognitive Impairment and Alzheimer's Disease

2. Which were your previous professions? (If the patient still works, he/she is asked about the present profession)

$\begin{array}{lll}\square & \square & \square \\ \text { Correct } & \text { Not correct } & \text { Does not remember } \\ 3 \text { points } & 2 \text { points } & 1 \text { point }\end{array}$

3. How do you spend your days? (If necessary: What is your favorite pastime?) Are these the same things you enjoyed in the past or have these activities changed?

$\begin{array}{lll}\square & \square & \square \\ \text { Significantly changed } & \text { Same as before } & \text { Does not know/remember } \\ 3 \text { points } & 2 \text { points } & 1 \text { point }\end{array}$

\section{Has your doctor given you a diagnosis? Which?}

$\begin{array}{lll}\square & \square & \square \\ \text { Relevant diagnosis } & \text { Irrelevant diagnosis } & \text { Does not remember } \\ 3 \text { points } & 2 \text { points } & 1 \text { point }\end{array}$

\section{What do you understand about the diagnosis?}

$\begin{array}{lll}\square & \square & \square \\ \text { Good understanding } & \text { Partial understanding } & \text { Does not know what it means } \\ 3 \text { points } & 2 \text { points } & 1 \text { point }\end{array}$

\section{How do your thinking and memory work for you?}

$\square$

Prominent cognitive symptoms 3 points $\square$

Some cognitive symptoms 2 points
No cognitive symptoms

1 point 


\section{Is this problematic to you?}

$\square$

Yes, very problematic 3 points
Yes, to some extent

2 points
No problems at all

1 point

\section{What do you think are the reasons for your cognitive problems?}

$\begin{array}{llll}\square & \square & \square & \square \\ \text { Association with relevant } & \text { Association with a relevant diagnostic } & \text { Association with illness, } & \text { Does not } \\ \text { diagnosis and illness } & \text { name, but without knowing the } & \text { but no diagnosis } & \text { know } \\ 4 \text { points } & \begin{array}{l}\text { implications of the diagnosis } \\ \text { 3 points }\end{array} & 2 \text { points } & 1 \text { point }\end{array}$

\section{How do you feel about your thinking and memory?}

$\begin{array}{lll}\square & \square & \square \\ \text { Worried (specified) } & \text { Generally but vaguely worried } & \text { Not worried } \\ 3 \text { points } & 2 \text { points } & 1 \text { point }\end{array}$

\section{Have you adjusted to your problems?}

$\begin{array}{lll}\square & \square & \square \\ \text { Yes, considerably } & \text { Yes, to some extent } & \text { No adaptation at all } \\ 3 \text { points } & 2 \text { points } & 1 \text { point }\end{array}$

Thank you.

Now we are turning to the task solutions.

\section{References}

1 Tononi G: Consciousness as integrated information: a provisional manifesto. Biol Bull 2008;215:216-242.

2 Butler AB: Hallmarks of consciousness. Adv Exp Med Biol 2012;739:291-309.

3 Wernicke C: Der aphasische Symptomencomplex (Breslau, Max Cohn \& Weigert, 1874); in Cohen RS, Wartofsky MW (eds): Boston Studies in the Philosophy of Science (transl 1969). Dordrecht, Reidel, 1969, vol IV, pp 34-97.

4 Anton G: Über Herderkrankungen des Gehirnes, welche von Patienten selbst nicht wahrgenommen werden. Wien Klin Wochenschr 1898;11:227-229.

5 Agnew SK, Morris RG: The heterogeneity of anosognosia for memory impairment in Alzheimer's disease: a review of the literature and a proposed model. Aging Ment Health 1998;2:7-19. 
6 Babinski MJ: Contribution à l'étude des troubles menteaux dans l'hemiplégie organique cérébrale (anosognosie). Rev Neurol (Paris) 1914;27:845-848.

7 Aalten P, van Valen E, Clare L, Kenny G, Verhey F: Awareness in dementia: a review of clinical correlates. Aging Ment Health 2005; 9:414-422.

8 Antoine C, Antoine P, Guermonprez P, Frigard B: Awareness of deficits and anosognosia in Alzheimer's disease (in French). Encephale 2004;30:570-577.

-9 Robinson RG: The Clinical Neuropsychiatry of Stroke, ed 2. Cambridge, Cambridge University Press, 2006, chapt 35.

10 Sedaghat F, Dedousi E, Baloyannis I, Tegos T, Costa V, Dimitriadis AS, Baloyannis SJ: Brain SPECT findings of anosognosia in Alzheimer's disease. J Alzheimers Dis 2010;21:641-647.

-11 Spalletta G, Girardi P, Caltagirone C, Orfei MD: Anosognosia and neuropsychiatric symptoms and disorders in mild Alzheimer disease and mild cognitive impairment. J Alzheimers Dis 2012;29:761-772.

12 Reed BR, Jagust WJ, Coulter L: Anosognosia in Alzheimer's disease: relationships to depression, cognitive function, and cerebral perfusion. J Clin Exp Neuropsychol 1993;15:231-244.

-13 Vogel A, Hasselbalch SG, Gade A, Ziebell M, Waldemar G: Cognitive and functional neuroimaging correlate for anosognosia in mild cognitive impairment and Alzheimer's disease. Int J Geriatr Psychiatry 2005;20:238-246.

14 Michon A, Deweer B, Pillon B, Agid Y, Dubois B: Relation of anosognosia to frontal lobe dysfunction in Alzheimer's disease. J Neurol Neurosurg Psychiatry 1994;57:805-809.

$>15$ Kashiwa Y, Kitabayashi Y, Narumoto J, Nakamura K, Ueda H, Fukui K: Anosognosia in Alzheimer's disease: association with patient characteristics, psychiatric symptoms and cognitive deficits. Psychiatry Clin Neurosci 2005;59:697-704.

16 Shibata K, Narumoto J, Kitabayashi Y, Ushijima Y, Fukui K: Correlation between anosognosia and regional cerebral blood flow in Alzheimer's disease. Neurosci Lett 2008;435:7-10.

$\checkmark 17$ Salmon E, Perani D, Herholz K, Marique P, Kalbe E, Holthoff V, et al: Neural correlates of anosognosia for cognitive impairment in Alzheimer's disease. Hum Brain Mapp 2006;27:588-597.

18 Tremont G, Alosco ML: Relationship between cognition and awareness of deficit in mild cognitive impairment. Int J Geriatr Psychiatry 2011;26:299-306.

19 Petersen RC: Mild cognitive impairment as a diagnostic entity. J Intern Med_2004;256:183-194.

20 Winblad B, Palmer K, Kivipelto M, Jelic V, Fratiglioni L, Wahlund L-O, et al: Mild cognitive impairment - beyond controversies, towards a consensus: report of the International Working Group on Mild Cognitive Impairment. J Intern Med 2004;256:240-246.

-21 Starkstein SE, Jorge R, Mizrahi R, Robinson RG: A diagnostic formulation for anosognosia in Alzheimer's disease. J Neurol Neurosurg Psychiatry 2006;77:719-725.

22 Hanyu H, Sakurai H, Hirao K, Shimizu S, Iwamoto T: Unawareness of memory deficits depending on cerebral perfusion pattern in mild cognitive impairment. J Am Geriatr Soc 2007;55:470-471.

-23 Turró-Garriga 0, Conde-Sala JL, Reñé-Ramírez R, López-Pousa S, Gascón-Bayarri J, Garre-Olmo J: Prevalence of anosognosia in Alzheimer's disease (in Spanish). Med Clin (Barc) 2014;143:13-19.

24 Breuer J, Freud S: Studies on Hysteria (Case 5) (transl. and edited by Strachey J, Strachey A). London, The Hogarth Press, 1956.

25 American Psychiatric Association: Diagnostic and Statistical Manual of Mental Disorders, Fourth Edition, Text Revision. Washington, American Psychiatric Association, 2000.

26 Stone J, Smyth R, Carson A, Warlow C, Sharpe M: La belle indifférence in conversion symptoms and hysteria: systematic review. Br J Psychiatry 2006;188:204-209.

27 Mendez MF, Shapira JS: Loss of emotional insight in behavioral variant frontotemporal dementia or 'frontal anosodiaphoria'. Conscious Cogn_2011;20:1690-1696.

28 Mendez MF, Shapira JS: Loss of insight and functional neuroimaging in frontotemporal dementia. J Neuropsychiatry Clin Neurosci 2005;17:413-416.

29 Korsakoff S: Etude médico-psychologique sur une forme des maladies de la mémoire. Rev Philos France Let 1889;28:501-530.

-30 Chen ST, Sultzer DL, Hinkin CH, Mahler ME, Cummings JL: Executive dysfunction in Alzheimer's disease: association with neuropsychiatric symptoms and functional impairment. J Neuropsychiatry Clin Neurosci 1998; 10:426-432.

-31 Mega MS, Dinov ID, Lee L, O’Connor SM, Masterman DM, Wilen B, Mishkin F, Toga AW, Cummings JL: Orbital and dorsolateral frontal perfusion defect associated with behavioral response to cholinesterase inhibitor therapy in Alzheimer's disease. J Neuropsychiatry Clin Neurosci 2000;12:209-218.

32 Hart AC, Hopkins AC (eds): International Classification of Diseases, 6th Ed, 9th Rev, Clinical Modification: ICD-9-CM Professional for Hospitals. Salt Lake City, Ingenix/St. Anthony Publishing, 2002, vol 1-3.

-33 Consensus recommendations for the postmortem diagnosis of Alzheimer's disease. The National Institute on Aging, and Reagan Institute Working Group on Diagnostic Criteria for the Neuropathological Assessment of Alzheimer's Disease. Neurobiol Aging 1997;18(suppl 4):S1-S2.

-34 Evers K, Kilander L, Lindau M: Insight in frontotemporal dementia: conceptual analysis and empirical evaluation of the consensus criterion 'loss of insight' in frontotemporal dementia. Brain Cogn 2007;63:13-23.

35 Souchay C: Metamemory in Alzheimer's disease. Cortex 2007;43:987-1003.

-36 Rankin KP, Baldwin E, Pace-Savitsky C, Kramer JH, Miller BL: Self awareness and personality change in dementia. J Neurol Neurosurg Psychiatry 2005;76:632-639. 
Lindau and Bjork: Anosognosia and Anosodiaphoria in Mild Cognitive Impairment and Alzheimer's Disease

-37 Kalbe E, Salmon E, Perani D, Holthoff V, Sorbi S, Elsner A, et al: Anosognosia in very mild Alzheimer's disease but not in mild cognitive impairment. Dement Geriatr Cogn Disord 2005;19:349-356.

38 Wechsler D: Wechsler Adult Intelligence Scale - Fourth Edition. San Antonio, Pearson, 2008.

39 Shulman K, Feinstein A: Quick Cognitive Screening for Clinicians. London, Martin Dunitz, Taylor and Francis Group, 2004.

40 Rey A: L'examen psychologique dans le cas d'encéphalopathie traumatique. Arch Psychol (Genève) 1941;28: 286-340.

41 Lezak MD, Howieson DB, Bigler ED, Tranel D: Neuropsychological Assessment, ed 5. New York, Oxford University Press, 2012.

42 Benton AL, Hamsher KS: Multilingual Aphasia Examination. Iowa City, University of Iowa, 1976.

43 Jones-Gotman M, Milner B: Design fluency: the invention of nonsense drawings after focal cortical lesions. Neuropsychologia 1977; 15:653-674.

44 Reitan RM, Wolfson D: The Halstead-Reitan Neuropsychological Test Battery: Theory and Clinical Interpretation. Tucson, Neuropsychology Press, 1993.

45 Tavakol M, Dennick R: Making sense of Cronbach's alpha. Int J Med Educ 2011;2:53-55.

-46 Clément F, Belleville S, Gauthier S: Cognitive complaint in mild cognitive impairment and Alzheimer's disease. J Int Neuropsychol Soc 2008;14:222-232.

47 Rosen HJ: Anosognosia in neurodegenerative disease. Neurocase 2011;17:231-241.

-48 Ausén B, Edman G, Almkvist 0, Bogdanovic N: Personality features in subjective cognitive impairment and mild cognitive impairment - early indicators of dementia? Dement Geriatr Cogn Disord 2009;28:528-535.

49 Lin F, Wharton W, Dowling NM, Ries ML, Johnson SC, Carlsson CM, et al: Awareness of memory abilities in community-dwelling older adults with suspected dementia and mild cognitive impairment. Dement Geriatr Cogn Disord 2010;30:83-92.

-50 Barrett AM, Eslinger PJ, Ballentine NH, Heilman KM: Unawareness of cognitive deficit (cognitive anosognosia) in probable AD and control subjects. Neurology 2005;64:693-699.

51 Hannesdottir K, Morris RG: Primary and secondary anosognosia for memory impairment in patients with Alzheimer's disease. Cortex 2007;43:1020-1030.

52 Gallo DA, Chen JM, Wiseman AL, Schacter DL, Budson AE: Retrieval monitoring and anosognosia in Alzheimer's disease. Neuropsychology 2007;21:559-568.

53 Galeone F, Pappalardo S, Chieffi S, Iavarone A, Carlomagno S: Anosognosia for memory deficit in amnestic mild cognitive impairment and Alzheimer's disease. Int J Geriatr Psychiatry 2011;26:695-701.

54 Starkstein SE, Chemerinski E, Sabe L, Kuzis G, Petracca G, Tesón A, Leiguarda R: Prospective longitudinal study of depression and anosognosia in Alzheimer's disease. Br J Psychiatry 1997;171:47-52.

55 Smith CA, Henderson VW, McCleary CA, Murdock GA, Buckwalter JG: Anosognosia and Alzheimer's disease: the role of depressive symptoms in mediating impaired insight. J Clin Exp Neuropsychol 2000;22:437-444.

56 Roberts JL, Clare L, Woods RT: Subjective memory complaints and awareness of memory functioning in mild cognitive impairment: a systematic review. Dement Geriatr Cogn Disord 2009;28:95-109.

57 Turró-Garriga 0, López-Pousa S, Vilalta-Franch J, Garre-Olmo J: Evaluation of anosognosia in Alzheimer's disease (in Spanish). Rev Neurol 2012;54:193-198.

58 Pia L, Conway PM: Anosognosia and Alzheimer's disease. Brain Impair 2008; 9:22-27.

59 Fagerland MW: t-tests, non-parametric tests, and large studies - a paradox of statistical practice? BMC Med Res Methodol 2012;12:78. 